\title{
Dayside convection and auroral morphology during an interval of northward interplanetary magnetic field
}

\author{
S. E. Milan ${ }^{1}$, M. Lester ${ }^{1}$, S. W. H. Cowley ${ }^{1}$, M. Brittnacher ${ }^{2}$ \\ ${ }^{1}$ Department of Physics and Astronomy, University of Leicester, Leicester LE1 7RH, UK \\ e-mail: Steve.Milan@ion.le.ac.uk \\ ${ }^{2}$ University of Washington, Geophysics Program, Box 351650, Seattle, Washington 98195, USA
}

Received: 20 September 1999 / Revised: 5 January 2000 / Accepted: 7 January 2000

\begin{abstract}
We investigate the dayside auroral dynamics and ionospheric convection during an interval when the interplanetary magnetic field (IMF) had predominantly a positive $B_{z}$ component (northward IMF) but varying $B_{y}$. Polar UVI observations of the Northern Hemisphere auroral emission indicate the existence of a region of luminosity near local noon at latitudes poleward of the dayside auroral oval, which we interpret as the ionospheric footprint of a high-latitude reconnection site. The large field-of-view afforded by the satellite-borne imager allows an unprecedented determination of the dynamics of this region, which has not previously been possible with ground-based observations. The location of the emission in latitude and magnetic local time varies in response to changes in the orientation of the IMF; the cusp MLT and the IMF $B_{y}$ component are especially well correlated, the emission being located in the pre- or post-noon sectors for $B_{y}<0 \mathrm{nT}$ or $B_{y}>0 \mathrm{nT}$, respectively. Simultaneous ground-based observations of the ionospheric plasma drift are provided by the CUTLASS Finland HF coherent radar. For an interval of IMF $B_{y} \approx 0 \mathrm{nT}$, these convection flow measurements suggest the presence of a clockwise-rotating lobe cell contained within the pre-noon dayside polar cap, with a flow reversal closely co-located with the high-latitude luminosity region. This pattern is largely consistent with recent theoretical predictions of the convection flow during northward IMF. We believe that this represents the first direct measurement of the convection flow at the imaged location of the footprint of the high-latitude reconnection site.
\end{abstract}

Key words: Magnetospheric physics (auroral phenomena; magnetopause, cusp, and boundary layers; plasma convection)

Correspondence to: S. Milan

\section{Introduction}

The dynamics of the dayside aurora and their relationship to the orientation of the interplanetary magnetic field (IMF) have received much attention recently. Of particular interest are the cusp aurora, the optical manifestation of the ionospheric footprint of the dayside reconnection region. The dayside contribution to the excitation of ionospheric convection lies within this region (Cowley and Lockwood, 1992); reconnection in the magnetotail provides the nightside contribution to the convection process, though it is on the dayside that we concentrate in this study. In general, reconnection is believed to occur where the magnetic fields in the magnetosheath and on the magnetopause have a component that is antiparallel. Hence, the location of the dayside reconnection site is mainly dependent on the $B_{z}$ (north-south) and $B_{y}$ (east-west) components of the IMF. When the IMF is directed southward, $B_{z}<0 \mathrm{nT}$, the "closed" terrestrial magnetic field lines which thread the subsolar magnetopause are interconnected with the IMF and become "open". The topology of the magnetosphere requires that this reconnection region maps to the ionospheric projection of the boundary between open and closed flux, or polar cap boundary, at the lowlatitude side of the footprint of the cusp. The forces acting upon these newly opened flux tubes cause their footprints in the ionosphere to move poleward, from the closed flux region into the open flux region. This motion, and the displacement of surrounding flux tubes due to the incompressible nature of the ionospheric plasma, constitutes convection. In general, along with the nightside reconnection contribution, this process produces the well-known twin-cell convection pattern, with antisunward flow across the polar cap and return flow at lower latitudes. However, the convection pattern is not so well understood for northward IMF. In this case, reconnection can take place at the high-latitude magnetopause, tailward of the magnetopause entrance to the cusp region (Reiff and Burch, 1985). Here, 
reconnection occurs between the IMF and pre-existing open flux in the magnetotail lobe. These field lines map to the high-latitude side of the ionospheric footprint of the cusp, and are now no longer constrained to be situated on the open/closed flux boundary, but can be located at higher latitude within the polar cap. No new open flux is created in this process, but the "lobe stirring" which results is thought to produce sunward flow in the dayside polar cap, as flux tubes are forced equatorward at the ionospheric footprint of the reconnection site, with a largely clockwise or anticlockwise circulatory pattern resulting if IMF $B_{y}$ is positive or negative. Supporting evidence for the presence of antisunward and sunward convection flow within the cusp region for southwardand northward-directed IMF, respectively, is found in the characteristic dispersion observed in precipitating cusp ions. Among others, Woch and Lundin (1992) have demonstrated that the average energy of injected ions falls with increasing latitude for $B_{z}<0 \mathrm{nT}$ and increases for $B_{z}>0 \mathrm{nT}$, related to time-of-flight considerations on newly merged field lines.

Ground-based optical observations of the auroral emission associated with the cusp region also provide supporting evidence for this picture. Cusp aurorae are observed to occur at lower latitudes (type 1 cusp aurora) for $B_{z}<0 \mathrm{nT}$ and higher latitudes (type 2 cusp aurora) for $B_{z}>0 \mathrm{nT}$ (e.g. Sandholt et al., 1996, 1998a, b, c, d; Øieroset et al., 1997), suggesting that the location of the reconnection region, at the subsolar or high-latitude magnetopause, differs depending on the orientation of the IMF. Indeed, type 1 and type 2 cusp aurorae are observed to co-exist under the conditions that the IMF is northward and has a significant $B_{y}$ component (for "clock angles" in the range $45^{\circ}<|\theta|<90^{\circ}$, see Sandholt et al., 1998d), an orientation of the IMF for which it is postulated reconnection can occur at the high- and low-latitude reconnection sites simultaneously (Reiff and Burch, 1985).

The $B_{y}$ component of the IMF introduces an eastwest asymmetry in the cusp emission. This asymmetry is relatively well-established for type 1 cusp aurora in which transient optical cusp features (often associated with intermittent reconnection) have an eastward or westward motion for $B_{y}<0 \mathrm{nT}$ or $B_{y}>0 \mathrm{nT}$, respectively (e.g. Sandholt et al., 1993), and Sandholt et al. (1988c) have suggested a general displacement of the cusp aurora toward pre- or post-noon for $B_{y}>0 \mathrm{nT}$ or $B_{y}<0 \mathrm{nT}$. However, such studies have suffered from a restricted field-of-view due to the use of ground-based instrumentation, and the large-scale dynamics are still not wholly understood. Though it has been anticipated that such a $B_{y}$-associated asymmetry exists for the type 2 cusp emission also (Sandholt et al., 1998b), it has not previously been directly observed.

This work presents observations of the dayside convection and auroral emission during an interval when the prevailing IMF conditions were $B_{z}, B_{y}>0 \mathrm{nT}$ $\left(0^{\circ}<\theta<90^{\circ}\right)$, as measured at the Wind spacecraft, though with brief excursions to other clock angle regimes. The auroral observations are provided by a spacecraft-borne imager, the ultra violet imager (UVI) onboard Polar (Torr et al., 1995). The measurements provided by this instrument have two advantages over previous ground-based observations of the cusp aurora. The first is the much larger field-of-view which can be achieved with a satellite imager. The second is that the imager makes measurements in the far ultraviolet wavelength regime, and FUV emission of the aurora is discernible against the sunlit hemisphere. Consequently, UVI observations of the dayside aurora can be made at all times of year, whereas ground-based optical measurements of the cusp are restricted to a relatively short observational window centred on winter solstice; the present observations were made under Northern Hemisphere summer conditions. Simultaneous measurements of the dayside ionospheric plasma drift from the CUTLASS Finland coherent HF radar, part of the SuperDARN network (Greenwald et al., 1995), are employed to resolve the convection flow pattern associated with the IMF-northward auroral configuration. The present observations allow the IMF $B_{y}$ influence on the location of the cusp emission to be determined for the first time, and demonstrate that the associated flow pattern is largely consistent with previously proposed theoretical models (Øieroset et al., 1997; Sandholt et al., 1998a, b, c).

\section{Observations and discussion}

During the interval of study, approximately 0600 UT to 1030 UT, 26 August, 1998, the Wind spacecraft was located $118 R_{e}$ upstream of the Earth. The IMF components and the solar wind dynamic pressure from this interval, as measured by the magnetic fields investigation (MFI) and solar wind experiment (SWE) instruments on Wind, are illustrated in Fig. 1. Throughout the interval, the solar wind velocity remained relatively uniform near $600 \mathrm{~km} \mathrm{~s}^{-1}$, giving an approximate delay to the Earth's bow shock of some $18 \mathrm{~min}$. An additional delay of a few minutes, the transit time of the shocked solar wind across magnetosheath, is expected before the IMF features observed by Wind impinge on the magnetopause. As will be discussed, a total solar wind propagation delay of $21 \mathrm{~min}$ appears to give the best correlation between variations observed in the IMF and the auroral response observed in the Earth's ionosphere. A solar wind shock was observed at 0640 UT: a sudden enhancement of the solar wind dynamic pressure from $2 \mathrm{nPa}$ to $10 \mathrm{nPa}$; thereafter the pressure decreased gradually, reaching $5 \mathrm{nPa}$ by 1000 UT. Between 0640 and 0920 UT $B_{z} \approx 10 \mathrm{nT}$, though with brief excursions to $B_{z}<0 \mathrm{nT}$ near 0655,0740 , and 0825 UT. Between 0640 and 0810 UT, $B_{y}$ varied back and forth between 10 and $-5 \mathrm{nT}$, with a brief excursion to $20 \mathrm{nT}$ at $0655 \mathrm{UT}$; between 0810 and $0910 \mathrm{UT} B_{y}$ progressed in a more gradual manner from 10 to $-10 \mathrm{nT}$. Over the entire interval, the $B_{x}$ component of the IMF varied relatively uniformly from $-15 \mathrm{nT}$ at $0640 \mathrm{UT}$ to $0 \mathrm{nT}$ at $1000 \mathrm{UT}$. It should be noted that this interval is somewhat exceptional in that the mean magnitude of the IMF is close to $20 \mathrm{nT}$. It is the dayside auroral and 

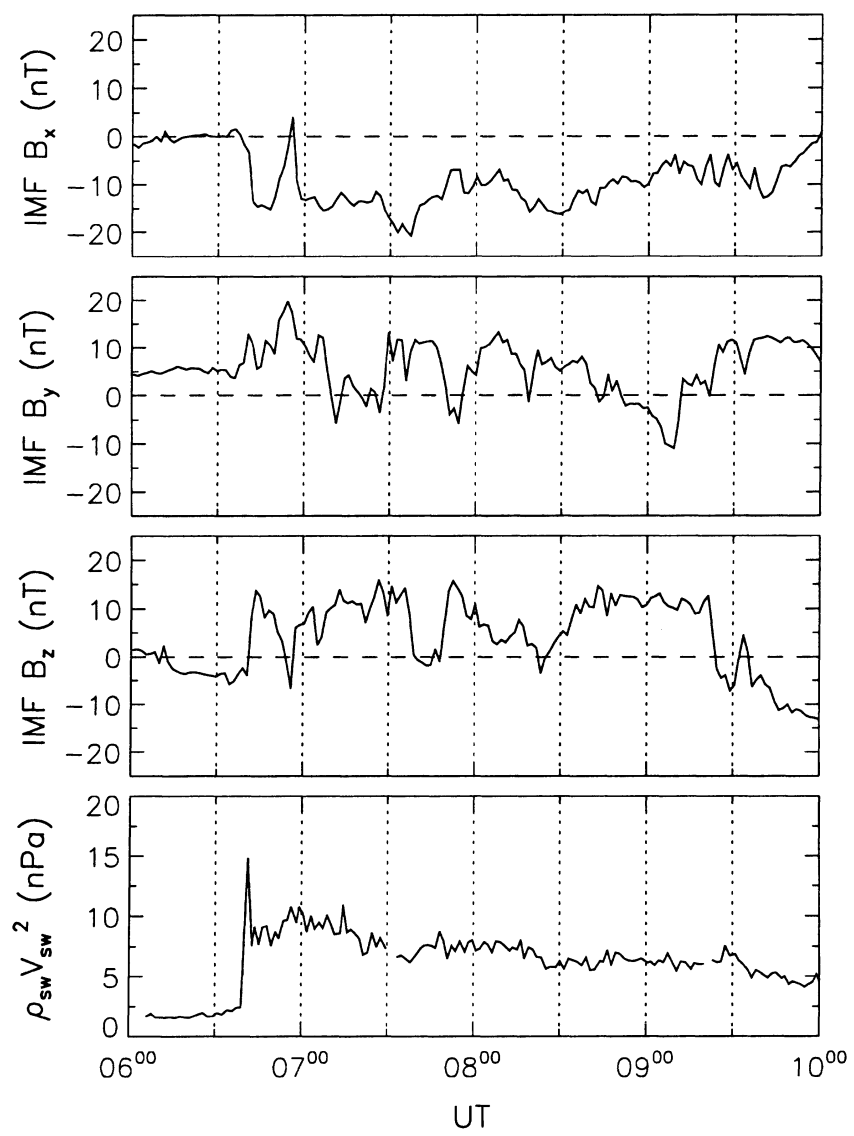

Fig. 1. Time series of IMF components $B_{x}, B_{y}$, and $B_{z}$, and solar wind dynamic pressure, as measured by the MFI and SWE instruments on Wind, from the interval 0600 UT to 1000 UT, 26 August, 1998

convection response to these variations in the IMF that this study concentrates on. The reader is directed to the study of Milan et al. (2000) for a description of the auroral and convection response to the southward turning of the IMF observed at approximately 0930 UT.

First, the dayside auroral observations from this interval are discussed. Polar UVI images of the Northern Hemisphere auroral luminosity, from between 0649 UT and 0949 UT, are presented in Fig. 2 in magnetic latitude and magnetic local time (MLT) polar coordinates; the latitudes shown are $70^{\circ}$ and $80^{\circ}$, and $12 \mathrm{MLT}$ is toward the top of each panel, with 06 and 18 MLT at the bottom right and left corners, respectively. At this time the images were acquired using the LBHs filter $(140-160 \mathrm{~nm})$ with a $36 \mathrm{~s}$ integration period approximately every $3 \mathrm{~min}$. Only those images which differ significantly from the previous image are shown; some of the panels have been marked with a letter to aid the following discussion. Since the ultraviolet auroral emissions in the LBHs wavelength range are attenuated by Schumann-Runge $\left(\mathrm{O}_{2}\right)$ absorption the brightness in the image is not directly proportional to the energy flux of the precipitating electrons but is influenced by their mean energy. Thus, the brighter portions of the image may be due to either a larger energy flux or a lower mean energy of the electrons. It should also be noted that the very lowest energy cusp electrons may not be detectable with this instrument, and that those regions of luminosity observed may be produced by electrons which have experienced some acceleration. However, these caveats do not affect the present analysis.

At 0649 UT (image A), before the solar wind dynamic pressure increase was incident on the Earth, the auroral oval was faint, located between latitudes of $75^{\circ}$ and $80^{\circ}$ on the dayside, with a more intense region between 14 and 16 MLT; this intense region in the main oval is a consistent feature throughout the interval of observation. After 0650 UT (B) the oval moved to lower latitude and increased significantly in intensity, in response to the solar wind pressure pulse. The delay between observation of the pressure step at Wind and the ionospheric response is $10 \mathrm{~min}$ here, less than $21 \mathrm{~min}$ discussed already; this suggests that the shock front was propagating faster than the solar wind. On the nightside (not shown) a great deal of auroral activity was observed following this onset, which did not subside totally until 0800 UT. On the dayside, the emission intensity in the main oval began to decrease after 0710 UT.

At 0713 UT (C) a small region of emission became apparent at a latitude of $82^{\circ}$, poleward of the main oval, near 14 MLT. It is this high-latitude region of auroral emission that is of most interest to the present study. We suggest that the appearance of this region of emission occurs in response to the northward turning of the IMF observed at 0640 UT and indeed, we will demonstrate later that subsequent to its initial observation, this emission region disappears and re-appears in response to variations in IMF $B_{z}$. Moreover, the local time at which the emission is situated is found to be strongly controlled by the $B_{y}$ component of the IMF. Over the 34 min following image C, until 0747 UT (D), this highlatitude emission region increased somewhat in size and intensity and progressed closer toward the noon sector. At 0750 UT (E) the high-latitude emission stepped to 15 MLT before drifting to lower latitude and merging with the main auroral emission by 0759 UT (F). This appears to be in response to the transition from IMF $B_{z} \approx 10 \mathrm{nT}$ to $B_{z} \approx 0 \mathrm{nT}$ observed at $0740 \mathrm{UT}$. No images were taken between 0805 UT and 0811 UT as the UVI camera was re-pointed to encompass the whole auroral zone. At 0811 UT $(\mathrm{G})$ the high-latitude emission region re-appeared at $81^{\circ}$ latitude, 13 MLT, whereafter it drifted poleward towards $84^{\circ}$ latitude at 0821 UT $(\mathrm{H})$. Subsequently, it drifted equatorward again before merging with the main oval at 0830 UT (I), again apparently in response to the reduction in IMF $B_{z}$ observed after $0800 \mathrm{UT}$. In the next image $(\mathrm{J})$, a region of high-latitude emission was once more observed, this time at $14 \mathrm{MLT}$ at a latitude of $79^{\circ}$. By 0848 UT (K) it had moved poleward to $84^{\circ}$ and to 15 MLT. Over the next $45 \mathrm{~min}$, until $0937 \mathrm{UT}(\mathrm{L})$, this emission progressed steadily from the post-noon sector to 10 MLT in the prenoon sector. This motion is apparently in response to the swing in IMF $B_{y}$ from $10 \mathrm{nT}$ to $-10 \mathrm{nT}$ observed 

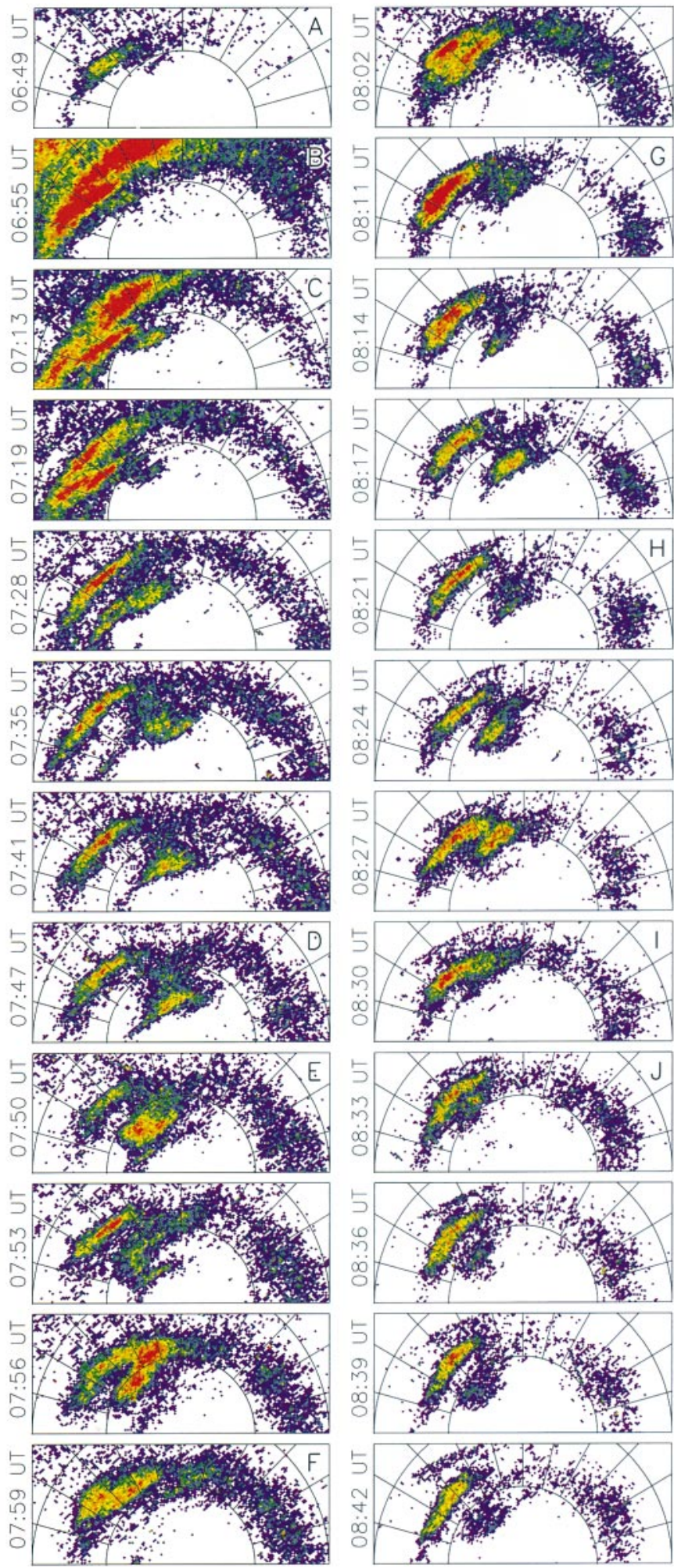

Fig. 2. A sequence of Polar UVI images, taken with the LBHs filter at an integration time of $36 \mathrm{~s}$. The images are displayed in polar magnetic latitude and MLT coordinates, with 12 MLT towards the top of each panel, and 06 and 18 MLT in the bottom right and left

between 0810 UT and 0910 UT. Finally, the highlatitude emission region returned to the post-noon sector by 0943 UT (M) before the dayside oval increased in intensity at $0946 \mathrm{UT}(\mathrm{N})$ in response to the southward
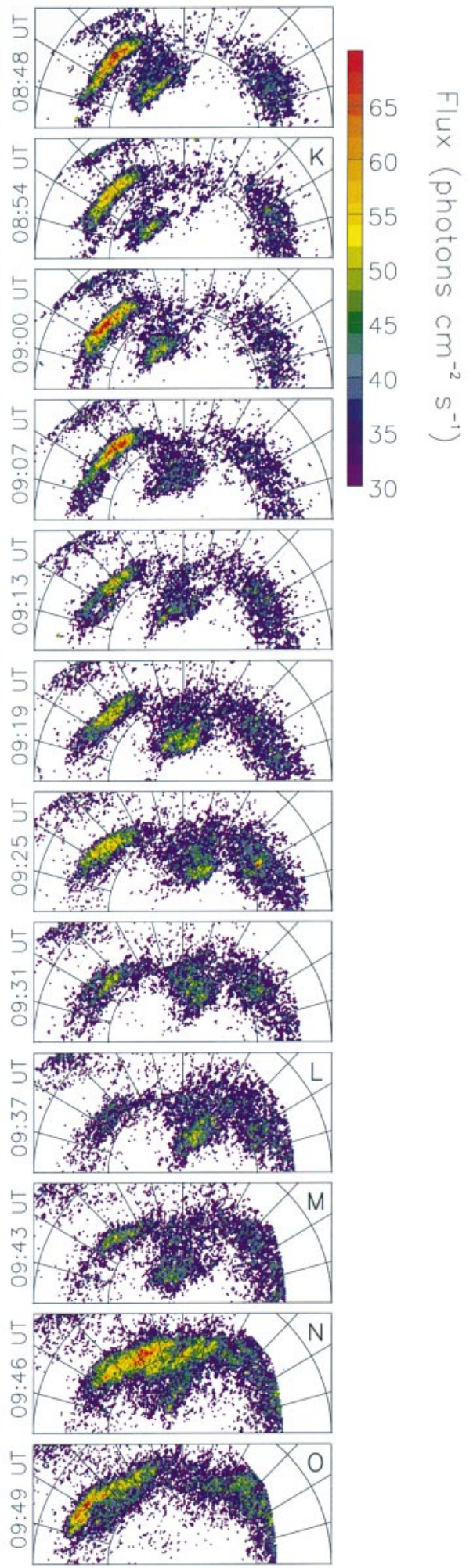

corners, respectively; the latitudes indicated are $70^{\circ}$ and $80^{\circ}$. The images are thresholded at 30 photons $\mathrm{cm}^{-2} \mathrm{~s}^{-1}$, to remove the sunlit background. Letters in the top right corner of some panels aid image identification in the text

turning of the IMF observed after 0920 UT. By 0949 UT $(\mathrm{O})$, the high-latitude emission region had disappeared.

The appearance of a high-latitude region of auroral emission during periods of northward IMF is consistent 

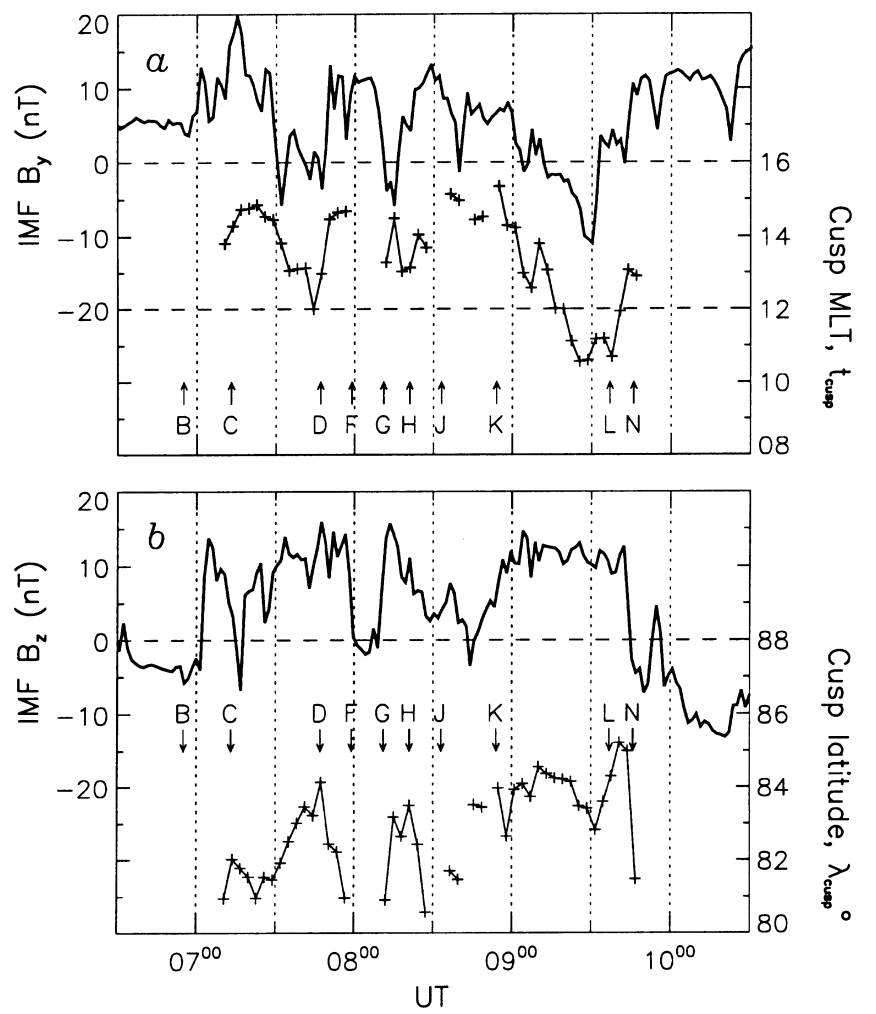

Fig. 3. Time series of the MLT and latitude of the centre of type 2 cusp emission (see text for details), compared with the $B_{y}$ and $B_{z}$ components of the IMF, as measured by the Wind MFI instrument, time-lagged by $21 \mathrm{~min}$ to account for the propagation delay in the solar wind. Lettered arrows correspond to images in Fig. 2

with previous ground-based observations of the cusp aurora, as discussed in the introduction. Consequently, we tentatively identify this region of luminosity as the optical signature of a high-latitude reconnection site, or in other words the type 2 cusp aurora. This interpretation is reinforced by the IMF $B_{y}$ control of the local time at which the luminosity appears, reconnection being the only mechanism by which such an influence can be exerted. To quantify the motion of the type 2 cusp aurora, the UVI images were analysed to find the "centre of gravity" of the dayside emission intensity poleward of $80^{\circ}$ latitude. For each available image the following analysis was applied. Pixels with intensity $I$ such that $I<I_{\min }$ were discarded to remove the background effect of the sunlit hemisphere; a threshold of $I_{\text {min }}=40$ photons $\mathrm{cm}^{-2} \mathrm{~s}^{-1}$ was employed. Then, within the latitude range $80^{\circ}<\lambda<90^{\circ}$ and the MLT range $06<t<18$, the intensity-weighted mean of latitude and MLT were calculated with

$\lambda_{\text {cusp }}=\frac{\sum_{\lambda} \sum_{t} \lambda I^{\prime}}{\sum_{\lambda} \sum_{t} I^{\prime}}$ and $t_{\text {cusp }}=\frac{\sum_{\lambda} \sum_{t} t I^{\prime}}{\sum_{\lambda} \sum_{t} I^{\prime}}$

where $I^{\prime}=I-I_{\min }$. Visual inspection indicates that the resulting values characterise well the centre of the cusp emission. Time series of $\lambda_{\text {cusp }}$ and $t_{\text {cusp }}$ are presented in Fig. 3; points are only indicated if more than 40 pixels contributed to the calculations; the typical number of pixels in each latitude and MLT determination was near
200. The $\lambda_{\text {cusp }}$ and $t_{\text {cusp }}$ time series are compared with the $B_{z}$ and $B_{y}$ components of the IMF, respectively, lagged by $21 \mathrm{~min}$ as this delay gives the best correlation between IMF precursors and the observed auroral response, as discussed already. Excellent agreement is found between the east-west motion of the high latitude cusp and changes in IMF $B_{y}$, in general the cusp moving towards the post-noon or pre-noon sectors for $B_{y}>0$ $\mathrm{nT}$ and $B_{y}<0 \mathrm{nT}$, most clearly observed between 0830 UT and $0930 \mathrm{UT}$ ( $\mathrm{J}$ to L). This motion is consistent with the predicted $B_{y}$ control of the location of the highlatitude reconnection site and hence type 2 cusp aurora (e.g. Sandholt et al., 1998b). Although the motion of the type 2 cusp emission in the east-west direction displays a remarkable correspondence with changes in IMF $B_{y}$, there is a large spread in values of $t_{\text {cusp }}$ at any particular value of $B_{y}$. This can be seen by comparing, for example, the location of the cusp near 0825 UT $\left(t_{\text {cusp }} \approx 13-14\right.$ MLT, $\left.B_{y} \approx 10 \mathrm{nT}\right)$ and 0855 UT $\left(t_{\text {cusp }} \approx 15\right.$ MLT, $B_{y} \approx 7 \mathrm{nT}$ ). This suggests that the location of the cusp is somewhat dependent on the past history of the IMF, or that it is dependent also on solar wind dynamic pressure or IMF $B_{x}$, both of which vary during the interval of study.

The sense of $B_{y}$ control of the type 2 cusp aurora just demonstrated is also consistent with that of the lowlatitude reconnection site for southward IMF (e.g. Cowley and Lockwood, 1992) and low altitude observations of cusp precipitation (Newell and Meng, 1988, 1989). However, this is opposite to the control exerted on the type 1 cusp aurora reported by Sandholt et al. (1998d) and the statistical location of cusp backscatter in HF radar observations during southward IMF (Provan et al., 1999). Provan et al. (1999) interpret this apparent contradiction as an elongation of the cusp radar aurora from the pre-/post-noon sector reconnection site into the post-/pre-noon sector through plasma convection on newly-reconnected field lines. This is also a possible mechanism for the extension of the optical aurora reported by Sandholt et al. (1998d), though we feel that the overall motion of the type 1 cusp aurora is not yet fully determined due to the small field-of-view of previous ground-based observations. Such a mechanism does not appear to be significant in the case of type 2 cusp aurora.

The IMF $B_{z}$ control of the latitude of the highlatitude cusp is not so clear as between $B_{y}$ and cusp MLT (Fig. 3b). However, the type 2 cusp was observed during northward IMF and disappeared during periods when IMF $B_{z}$ was near-zero or negative. With each transition from $B_{z}<0 \mathrm{nT}$ to $B_{z}>0 \mathrm{nT}$, the type 2 cusp aurora appeared at a latitude just poleward of the main dayside oval and subsequently drifted poleward; conversely, in the opposite sense of $B_{z}$ transition, the cusp emission appeared to drift equatorward towards the main oval before merging with it or fading. The first case is consistent with ideas proposed by Øieroset et al. (1997) and Sandholt et al. (1998a), in which reconnection at the high-latitude magnetopause drives sunward convection at the cusp footprint in the ionosphere. This leads to the accumulation of newly opened flux equa- 


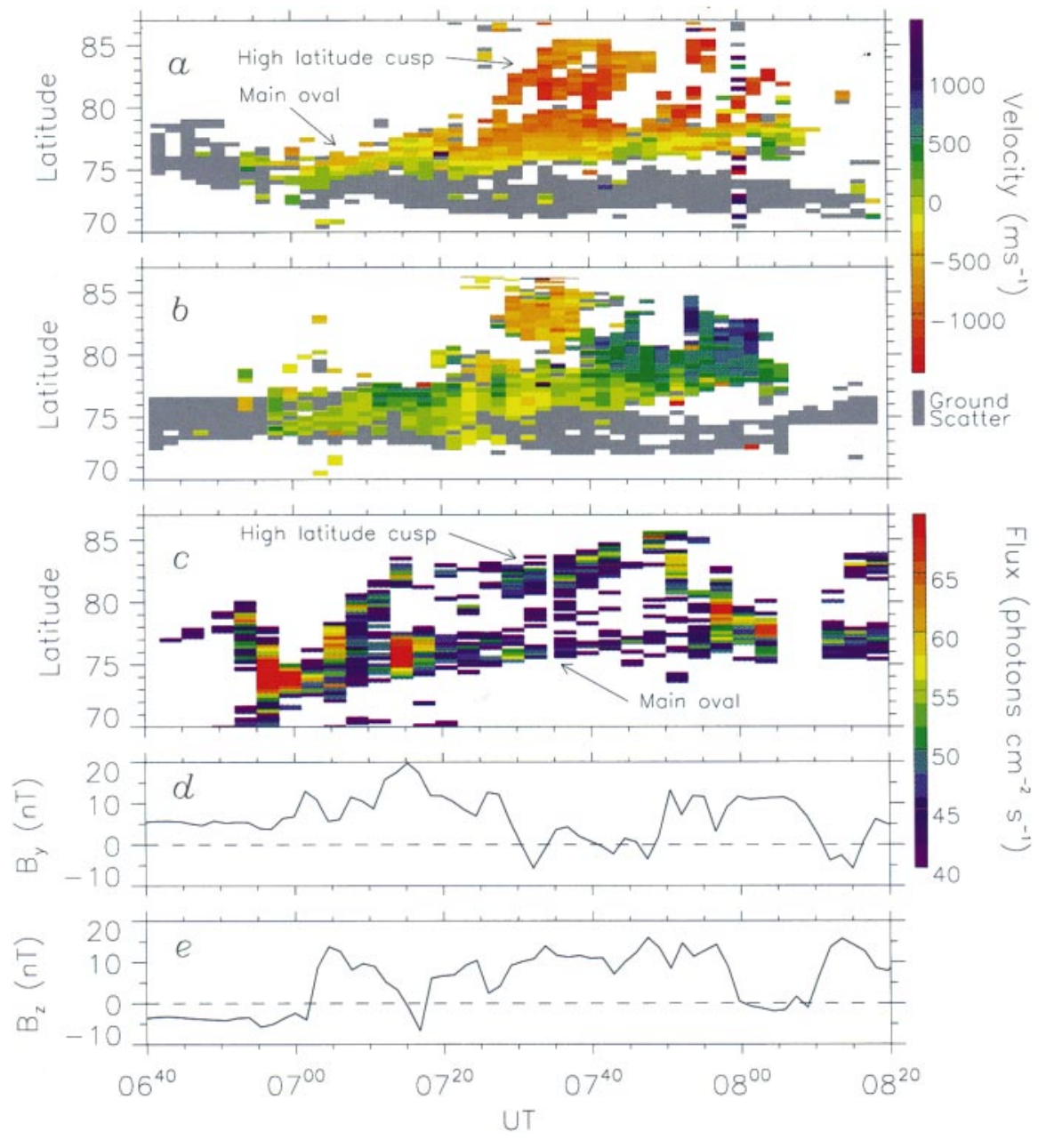

Fig. 4. a, b Latitude-time-velocity plots from beams 5 and 9 of the CUTLASS Finland HF coherent radar. c Latitudetime-photon flux plot from the 14 MLT meridian of Polar UVI images taken with the LBHs filter. d, e IMF $B_{y}$ and $B_{z}$ components measured by the Wind MFI instrument, lagged by $21 \mathrm{~min}$ to account for the propagation delay in the solar wind torward of the cusp, and hence a separation develops between the cusp and the main oval.

The convection observations are now presented. Ionospheric plasma drift measurements from the CUTLASS Finland HF coherent radar are available from a subset of the interval described, 0650 UT to 0815 UT. A summary of the CUTLASS plasma flow observations is presented in Fig. 4a, b, line-of-sight velocity measurements from beam 5 and beam 9 of the radar being displayed as a function of Universal Time and magnetic latitude. Positive (negative) velocities indicate plasma flow toward (away from) the radar; grey represents ground scatter which will not be discussed further. For comparison, the Polar UVI observations from this interval are summarised in Fig. 4c, in which the optical intensity along the 14 MLT meridian is presented in a latitude-time format also (a data gap exists between 0805 UT and $0811 \mathrm{UT}$ ). The IMF $B_{y}$ and $B_{z}$ components are shown in Fig. 4d, e for comparison; again, a lag of $21 \mathrm{~min}$ has been applied to these time series, as in Fig. 3. A brightening of the main optical oval, located near $73^{\circ}$ latitude, is observed at $0655 \mathrm{UT}$, in response to the step in the solar wind dynamic pressure observed at 0640 UT. After 0700 UT, the main auroral oval gradually progresses poleward, reaching $77^{\circ}$ latitude by 0820 UT. The radar observes a backscatter counterpart of the main optical oval, which is first observed near $75^{\circ}$ latitude, at the time of the auroral brightening, 0655 UT. This region of backscatter is then observed to progress poleward to $78^{\circ}$ by 0810 UT. Thereafter, backscatter ceases to be observed as a consequence of deleterious HF propagation conditions. After $0705 \mathrm{UT}$, following the northward turning of the IMF, the optical emission bifurcates, the region poleward of $80^{\circ}$ being the high latitude cusp emission described already; this region moves equatorward and disappears again between 0755 UT and 0810 UT when IMF $B_{z} \approx 0$ nT. Between 0728 UT and 0750 UT, an addition region of radar backscatter is observed poleward of the main oval, between latitudes of $80^{\circ}$ and $85^{\circ}$. We equate this region of backscatter with the type 2 cusp aurora observed by the UVI imager. The time interval over which this high latitude backscatter region is observed corresponds to the period when IMF $B_{y} \approx 0 \mathrm{nT}$, as will be discussed below.

Figure 5 presents a comparison of Polar UVI images of the dayside auroral emission intensity with nearsimultaneous radar measurements of the line-of-sight component of the plasma drift speed. Both are presented in the same magnetic latitude and MLT polar coordinates as Fig. 2. A statistical oval and the radar fieldof-view are superimposed on each panel to aid the eye. 

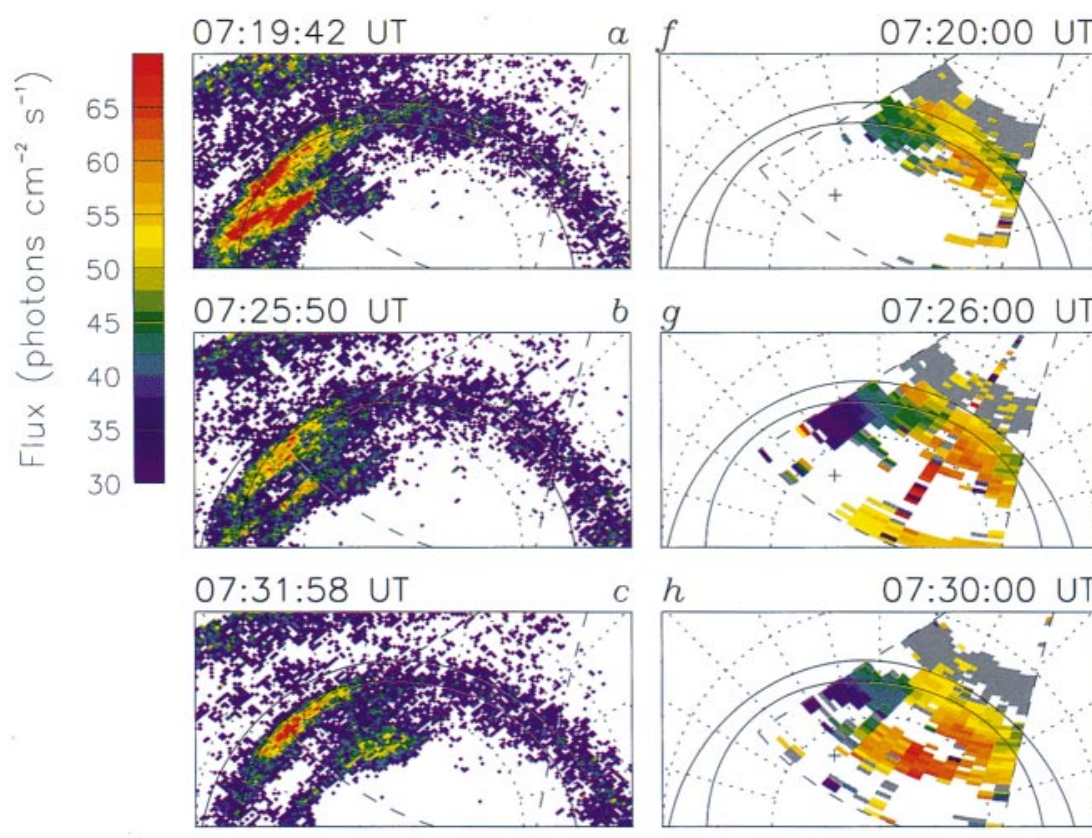

c
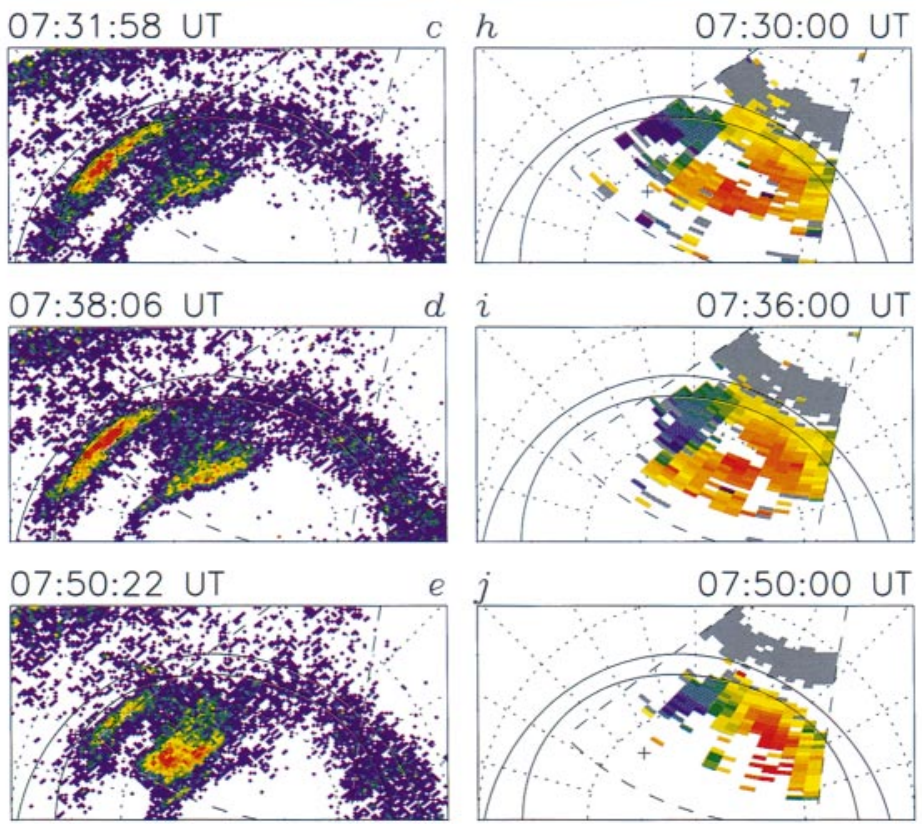

Fig. 5. a-e Polar UVI images of the dayside Northern Hemisphere, in magnetic latitude and MLT coordinates, in the same format as Fig. 2, from selected times for comparison with radar observations. Superimposed is a statistical auroral oval and the location of the radar field-ofview. $\mathbf{f}-\mathbf{j}$ Line-of-sight velocity maps from CUTLASS Finland radar scans corresponding to the Polar UVI images in $\mathbf{a}-\mathbf{e}$
In all the Polar UVI images (Fig. 5a-e) the type 2 cusp aurora is observed poleward of the main auroral oval. At 0720 UT (Fig. 5a) this emission is located in the postnoon sector, consistent with the prevailing IMF orientation, $B_{y}>0 \mathrm{nT}$. Between $0730 \mathrm{UT}$ and $0745 \mathrm{UT}$, however, the cusp aurora moves toward local noon (Fig. 5b-d), during an interval when $B_{y} \approx 0 \mathrm{nT}$ (see Fig. 4d). After this time, as once again $B_{y}>0 \mathrm{nT}$, the cusp aurora moves back toward the post-noon sector, as observed for instance at 0750 UT (Fig. 5e). In the radar observations at 0720 UT (Fig. 5f) a region of ionospheric backscatter is observed between $74^{\circ}$ and $80^{\circ}$ latitude, corresponding to the main auroral oval, as identified in Fig. 4a, b. This region of backscatter is divided into two latitudinal regimes: above approximately $76^{\circ}$, velocities are negative in the western-most beams and vary gradually to positive velocities in the eastern-most beams; this situation is reversed below $76^{\circ}$ latitude. Such a pattern of line-of-sight velocities is consistent with eastward (sunward) plasma flow at low latitudes and westward (antisunward) plasma flow at high latitudes, separated by a convection reversal boundary located near a latitude of $76^{\circ}$. This is the plasma flow expected in an anticlockwise-rotating dawn convection cell, a situation indicated schematically in Fig. 6a. Such convection flow is usually associated with low-latitude reconnection during intervals of southward IMF. However, the IMF at this time is orientated northward, and indeed type 2 cusp aurora are observed, indicative of high-latitude reconnection. The existence of this dawn convection cell has three possible explanations. In the first instance, this flow could be the remnant of twin-cell convection excited prior to 0705 UT when $B_{z}<0 \mathrm{nT}$; the response time of the ionospheric flow to changes in IMF orientation is thought to be of the order of 15 min (Cowley and Lockwood, 1992). Secondly, at 0720 UT, IMF $B_{y} \approx B_{z}$, a condition under which high- and low-latitude reconnection can coexist (Reiff and Burch, 1985; Sandholt et al., 1998b, d). Finally, considerable substorm activity is on-going during this interval, the magnetospheric response to the solar wind pressure pulse observed at 0640 UT (Milan et al., 2000), and the observed convection flow could be the dayside response to the nightside convec- 

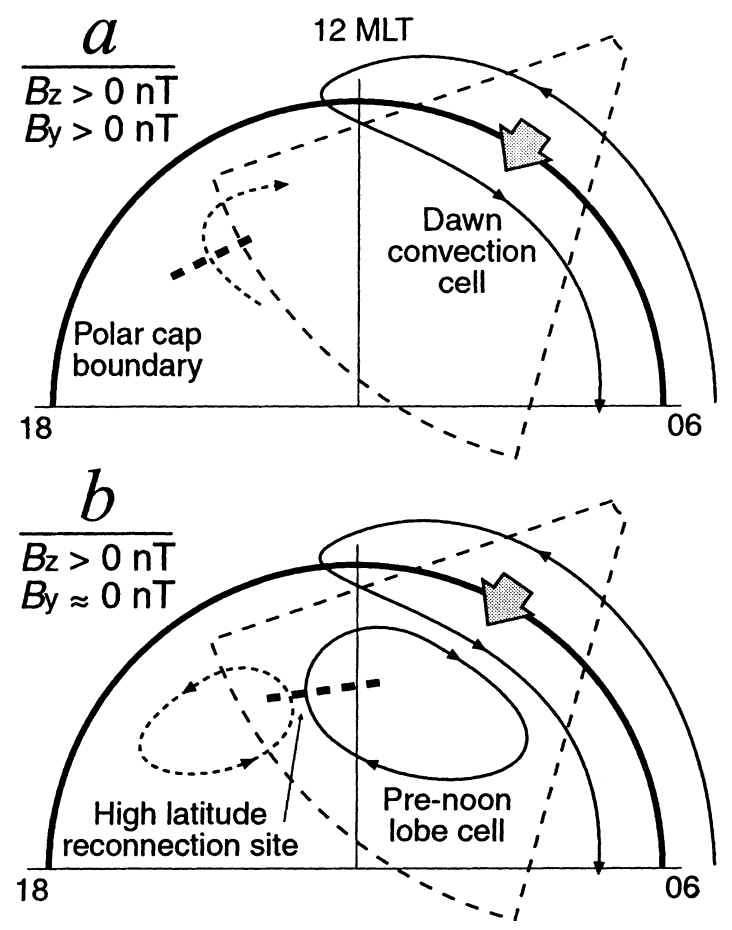

Fig. 6a, b. A schematic diagram of the convection flow pattern observed for IMF $B_{z}>0 \mathrm{nT}$ and $\mathbf{a} B_{y}>0 \mathrm{nT}$ or b $B_{y} \approx 0 \mathrm{nT}$. Local noon is toward the top of the figure. The heavy solid line indicates the location of the adiaroic polar cap boundary, and the heavy dashed line indicates the ionospheric footprint of the highlatitude reconnection line. The open arrow shows the motion of the adiaroic boundary. The light arrowed lines represent plasma stream lines. Dotted stream lines show the predicted location of flows not observed by the radar. The radar field-of-view is shown for context

tion excitation; indeed, the poleward motion of the main auroral oval observed throughout the interval of investigation is consistent with the closure of open flux on the nightside. This dawn cell convection flow, and especially the antisunward flow at higher latitudes, is present in the region of the main oval throughout the interval illustrated in Figs. 4 and 5.

As the type 2 cusp aurora intensifies and moves toward local noon, to a location significantly within the radar field-of-view, a region of backscatter appears poleward of $80^{\circ}$ latitude (Fig. $5 \mathrm{~h}, \mathrm{i}$ ); this is the region of high latitude backscatter identified in Fig. 4a, b. The line-of-sight velocities associated with this backscatter are negative in the western beams and positive in the eastern beams, with a sharp reversal in the velocities in the noon sector near a latitude of $81^{\circ}$. This pattern of velocities suggests eastward flow poleward and westward flow equatorward of the reversal, with the velocity reversal closely co-located with the type 2 cusp aurora. We interpret this velocity signature as a clockwiserotating convection cell, contained within the polar cap, driven by the high-latitude reconnection site, as illustrated schematically in Fig. 6b. This lobe cell is associated with sunward flow in the noon sector polar cap, as was observed by Taylor et al. (1998) following a northward turning of the IMF. This convection flow behaviour is largely consistent with theoretical patterns proposed by Øieroset et al. (1997) and Sandholt et al. (1998a, b, c) for IMF $B_{z}>0 \mathrm{nT}$. However, these models suggest that for $B_{y} \approx 0 \mathrm{nT}$, a corresponding anticlockwise-rotating lobe convection cell should be present in the post-noon sector (sketched in Fig. 6b); the present observations do not allow the existence of such a cell to be verified. In the present case the pre-noon lobe cell appears to extend a considerable distance into the post-noon sector. It is expected that for $B_{y}>0 \mathrm{nT}$, a single clockwise-rotating lobe cell should exist (the possible location of this cell is sketched in Fig. 6a). As $B_{y}$ approaches $0 \mathrm{nT}$, an anticlockwise-rotating cell should grow in the post-noon sector, displacing the clockwiserotating cell into the pre-noon sector, and over time the two lobe cells should become equal in size. Perhaps, in the present case, $B_{y}$ does not remain near-zero for a sufficient length of time for this equilibrium position to be attained, and that, as indicated in Fig. 6b, the prenoon cell remains enlarged, and a smaller cell, outside the radar field-of-view, exists in the post-noon sector.

By 0750 UT, the type 2 cusp aurora has moved back into the post-noon sector under the influence of IMF $B_{y}>0 \mathrm{nT}$. Concordantly, the region of radar backscatter associated with this emission disappears, and all that remains is the backscatter associated with the main oval, in which predominantly antisunward flow in the dawn cell is observed (Fig. 5j).

\section{Summary and conclusions}

This study has presented coordinated observations from a spacecraft imager, the Polar UVI instrument, and the CUTLASS Finland HF coherent radar, during an interval of predominantly northward IMF. The spacecraft imager gives an unprecedented view of the dayside auroral dynamics. At times when IMF $B_{z}>0 \mathrm{nT}$, a region of auroral emission is observed poleward of the dayside auroral oval. We interpret this emission as type 2 cusp aurora (Sandholt et al., 1998d), and hence as the optical manifestation of high-latitude reconnection, possibly on open lobe field lines. The local time position of this emission is strongly dependent on the prevailing east-west component of the IMF, being located in the pre- or post-noon sector for IMF $B_{y}<0 \mathrm{nT}$ and $B_{y}>0$ nT, respectively, as predicted by Sandholt et al. (1998b).

During the study interval, the radar was situated in the pre-noon sector. At times when radar observations were available, a region of backscatter appeared colocated with the main optical auroral oval. Within this backscatter, convection flows were observed, consistent with dawn cell antisunward flow within the polar cap and return flow at lower latitudes. These flows were observed for northward IMF conditions, despite this pattern usually being associated with southward IMF, suggesting a significant contribution to the convection process from nightside reconnection. When $B_{y}>0 \mathrm{nT}$, the ionospheric footprint of the high-latitude reconnection site, the optical manifestation of which is type 2 cusp aurora, was located in the post-noon sector, away from the viewing area of the radar. However, during an 
interval of $B_{y} \approx 0 \mathrm{nT}$, the cusp emission moved into the field-of-view of the radar, and an associated region of backscatter was observed. In other words, the highlatitude cusp region appears to act as a target for $\mathrm{HF}$ radars (for a fuller discussion of the conditions necessary for the observation of radar backscatter see Milan et al., 1998). The flows observed within this region of backscatter were consistent with a clockwise-rotating convection cell contained mainly within the pre-noon dayside ionosphere, as predicated by Øieroset et al. (1997) and Sandholt et al. (1998a, b, c), though the existence of a corresponding anticlockwise-rotating cell in the post-noon sector could not be verified. We believe that this represents the first direct observation of the flow pattern associated with type 2 cusp aurora and hence high-latitude reconnection. These observations lend credence to theoretical models of reconnection and the excitation of ionospheric convection for northward IMF.

Acknowledgements. CUTLASS is supported by the Particle Physics and Astronomy Research Council (PPARC grant PPA/R/R/ 1997/00256), UK, the Swedish Institute for Space Physics, Uppsala, and the Finnish Meteorological Institute, Helsinki. We thank the principle investigators, R.P. Lepping and K. Ogilvie, for the use of key parameters from the Wind MFI and SWE instruments, respectively. SEM is supported by PPARC grant PPA/G/0/1997/ 000254.

The Editor-in-chief thanks P. Newell for his help in evaluating this paper.

\section{References}

Cowley, S. W. H., and M. Lockwood, Excitation and decay of solar-wind driven flows in the magnetosphere-ionosphere system, Ann. Geophysicae, 10, 103, 1992.

Greenwald, R. A., K. B. Baker, J. R. Dudeney, M. Pinnock, T. B. Jones, E. C. Thomas, J.-P. Villain, J.-C. Cerisier, C. Senior, C. Hanuise, R. D. Hunsucker, G. Sofko, J. Koehler, E. Nielsen, R. Pellinen, A. D. M. Walker, N. Sato, and H. Yamagishi, DARN/SuperDARN: a global view of the dynamics of highlatitude convection, Space Sci. Rev., 71, 761-796, 1995.

Milan, S. E., M. Lester, S. W. H. Cowley, and M. Brittnacher, Convection and auroral response to a southward tuning of the IMF: Polar UVI, CUTLASS, and IMAGE signatures of transient magnetic flux transfer at the magnetopause, J. Geophys. Res., in press, 2000.

Milan, S. E., T. K. Yeoman, and M. Lester, The dayside auroral zone as a hard target for coherent HF radars, Geophys. Res. Lett., 25, 3717, 1998.
Newell, P. T., and C.-I. Meng, The cusp and the cleft/boundary layer: low-altitude identification and statistical local time variation, J. Geophys. Res., 93, 14549, 1988.

Newell, P. T., C.-I. Meng, D. G. Sibeck, and R. Lepping, Some lowaltitude cusp dependencies on the interplanetary magnetic field, J. Geophys. Res., 94, 8921, 1989.

Øieroset, M., P. E. Sandholt, W. F. Denig, and S. W. H. Cowley, Northward interplanetary magnetic field cusp aurora and highlatitude magnetopause reconnection, J. Geophys. Res., 102, $11349,1997$.

Provan, G., T. K. Yeoman, and S. W. H. Cowley, The influence of the IMF $B_{y}$ component on the location of pulsed flows in the dayside ionosphere observed by an HF radar, Geophys. Res. Lett., 26, 521, 1999.

Reiff, P. H., and J. L. Burch, IMF $B_{y}$-dependent plasma flow and Birkeland currents in the dayside magnetosphere, 2. A global model for northward and southward IMF, J. Geophys. Res., 90, $1595,1985$.

Sandholt, P. E., J. Moen, D. Opsvik, W. F. Denig, and W. J. Burke, Auroral event sequence at the dayside polar cap boundary: signature of time-varying solar wind-magnetosphere-ionosphere coupling, Adv. Space Res., 13, (4)7, 1993.

Sandholt, P. E., C. J. Farrugia, P. Stauning, S. W. H. Cowley, and T. Hansen, Cusp/cleft auroral forms and activities in relation to ionospheric convection: responses to specific changes in solar wind and interplanetary magnetic field conditions, J. Geophys. Res., 101, 5003, 1996.

Sandholt, P. E., C. J. Farrugia, and S. W. H. Cowley, Pulsating cusp aurora for northward interplanetary magnetic field, J. Geophys. Res., 103, 26 507, 1998a.

Sandholt, P. E., C. J. Farrugia, J. Moen, and S. W. H. Cowley, Dayside auroral configurations: Responses to southward and northward rotations of the interplanetary magnetic field, J. Geophys. Res., 103, 20 279, 1998b.

Sandholt, P. E., C. J. Farrugia, J. Moen, S. W. H. Cowley, and B. Lybekk, Dynamics of the aurora and associated convection currents during a cusp bifurcation event, Geophys. Res. Lett., 25, 4313, 1998c.

Sandholt, P. E., C. J. Farrugia, J. Moen, Ø. Noraberg, B. Lybekk, T. Sten, and T. Hansen, A classification of dayside auroral forms and activities as a function of interplanetary magnetic field orientation, J. Geophys. Res., 103, 23 325, 1998d.

Taylor, J. R., S. W. H. Cowley, T. K. Yeoman, M. Lester, T. B. Jones, R. A. Greenwald, G. Sofko, J.-P. Villain, R. P. Lepping, and M. R. Hairston, SuperDARN studies of the ionospheric convection response to a northward turning of the interplanetary magnetic field, Ann. Geophysicae, 16, 549, 1998.

Torr, M. R., D. G. Torr, M. Zukic, R. B. Johnson, J. Ajello, P. Banks, K. Clark, K. Cole, C. Keffer, G. Parks, B. Tsurutani, and J. Spann, A far ultraviolet imager for the international solar-terrestrial physics mission, Space Sci. Rev., 71, 329, 1995.

Woch, J., and R. Lundin, Magnetosheath plasma precipitation in the polar cusp and its control by the interplanetary magnetic field, J. Geophys. Res., 97, 1421, 1992. 